\title{
¿Encuentro estremecedor de todas las sangres? Sobre la maternidad de José María Arguedas
}

\author{
Ghislaine Delaune-Gazeau
}

Propongo una pesquisa en la vida y obra de José María Arguedas y en escritos de sus biógrafos y críticos, para poner de relieve las dudas en torno de su filiación consanguínea. No es descabellado pensar que corría por sus venas sangre materna indígena y es probable que él no lo supiera con exactitud. Que no supiera quién era, también es probable. Pero identificar con certeza esa filiación no ha sido parte de las preocupaciones de la mayoría de estudiosos de la vida y obra de Arguedas; incluso se podría decir que deliberadamente se ha optado por perpetuar el desconocimiento. Como es sabido, Arguedas nació en Apurímac en el verano de 1910 a 1911 y, derramando esas sangres, se dio un tiro en la sien el 28 de noviembre de 1969 y falleció el 2 de diciembre a la edad de 58 años.

En la primera parte expondré versiones biográficas a las que he tenido acceso y luego estudiaré las razones por las que no se discute la versión andahuaylina, así como la imposibilidad de que esta sea cierta, para acercarnos a la mujer que dio a luz a nuestro autor. Convencida como estoy de su doble ascendencia cultural, añadiré algunas reflexiones y argumentos a mi tesis, para terminar con evocaciones rápidas de un ejemplo en algo similar, cosechadas en mis lecturas de psicología, que contribuirán a esclarecer estas brumas.

\section{¿CÓMO SURGIERON LAS DUDAS SOBRE LA FILIACIÓN DEL ESCRITOR?}

Leí por primera vez Los ríos profundos a principios de los años ochenta en Abancay, capital del departamento surandino de Apurímac. Quien me prestó la novela comentó que el autor había nacido en un distrito cercano al cañón del río Apurímac, que era hijo adulterino de Víctor Manuel Arguedas, abogado itinerante, y de una indígena quechuahablante, sierva en una hacienda del distrito. La novela, que se desarrolla en gran parte en la ciudad de Abancay, despertó en mí un interés inmediato. 
Un tiempo después leí las Memorias de Luis E. Valcárcel, famoso historiador, amigo entrañable de José María, a quien presenta de este modo: “A Arguedas suele reconocérsele como un destacadísimo literato, pero también hay que mencionar su importante labor en el campo etnológico y folclórico. Además, debo añadir que nos unía una afectuosa relación" (1981, p. 370).

Valcárcel hace hincapié en su aprecio por la obra antropológica y literaria de Arguedas y además resalta la profunda amistad que los unía, sugiriendo incluso un trato confidencial de parte de su joven amigo, como si quisiera advertir solapadamente que no hay que dudar de lo que viene a continuación:

José María fue hijo natural de un abogado de vida irregular, cuyo trabajo lo llevaba de una parte a otra. Este abogado era natural de Cusco, donde estuvo un tiempo, pero luego continuó su vida errante trasladándose a Ayacucho y otros pueblos de la sierra. En Apurímac tuvo a su hijo José María, quien en un primer momento lo acompañaba en sus viajes. (Valcárcel, 1981, p. 370)

Valcárcel conocía los esfuerzos de José María por liberarse del peso de un secreto. Lo deja entrever en la franqueza de su testimonio, como si fuera un hecho normal y conocido, y no como algo difícil de develar, a pesar de múltiples intentos en sus escritos y discursos.

Sin embargo, el historiador no da mayores precisiones. ¿Acaso se lo advirtió el mismo Arguedas? Es posible que, durante los numerosos viajes que hicieron juntos cuando trabajaban en el Ministerio de Educación, Arguedas le confiara su inquietud por identificar a su madre biológica, a su propia identidad cultural, porque se sentía más indio, más propio de la cultura quechua que del mundo blanco.

Años después, al empezar mi investigación sobre un tema indigenista para un posgrado en literatura hispanoamericana (Delaune-Gazeau, 1991), leí y analicé novelas y cuentos de otros escritores andinos y, de nuevo, los de Arguedas. Fue entonces cuando me enteré de que su biografía oficial, en lo que atañe a su primera infancia, era muy diferente de lo que me habían dicho en Abancay y, sobre todo, de lo que publicó Valcárcel en cuanto al lugar de nacimiento, la cultura y el estatus de la madre. Así hubiera nacido el 18 de enero de 1911 en Andahuaylas, provincia de Apurímac:

[...] fue hijo de la Sra. Victoria Altamirano de Arguedas, de familia distinguida de San Pedro de Andahuaylas, y del abogado Víctor Manuel Arguedas Arellano, natural del Cusco, hombre blanco y apuesto, figura principal en los pueblos sureños que recorre por razón del cargo. (Merino de Zela, 1991, p. 99)

Victoria falleció el 3 de abril de 1914, cuando José María tenía tres años. El niño, entonces, habría sido entregado al cuidado de su abuela en Andahuaylas. Tras tres años de viudez, Víctor Manuel volvió a casarse. Escribe Mildred Merino de Zela: 
En 1917 se casa con la acaudalada matrona de San Juan de Lucanas, doña Grimanesa Arangoitia vda. de Pacheco quien tenía tres hijos. [...] Este matrimonio determina al doctor mandar recoger a José María; comisiona a don Ramón Escajadillo, quien viaja especialmente a Andahuaylas para traer al niño. (Merino de Zela, 1991, p. 100)

Se impone entonces la pregunta, ¿en qué difieren las versiones? Cotejando la de Valcárcel con la de Merino de Zela, destaca en la última la voluntad de integrar definitivamente a José María, por el origen de sus padres, en un nivel sociocultural 'por encima' de los indios, entre los blancos o mistis. Ambos autores están de acuerdo en cuanto al departamento en donde nació José María, Apurímac, pero Valcárcel habla de un distrito no nombrado de la provincia primaveral de Abancay, la capital del departamento, mientras que Merino de Zela cita a Andahuaylas, la fría capital de la provincia rival.

Merino de Zela insiste en las apariencias raciales y sociales de los padres: la distinción familiar del lado materno y la importancia del cargo del padre, "hombre blanco y apuesto". Más escueto, discreto y puntilloso, Valcárcel señala la escasa moralidad del padre: su "vida irregular"; lo de "hijo natural", en el contexto, implica la violación de una india. Lo mismo en cuanto al abandono del hijo en una comunidad indígena:

Luego fue abandonado en una comunidad del mismo departamento de su nacimiento, cuando solo contaba cuatro o cinco años de edad. El desarrollo de su infancia en una comunidad indígena fue un elemento esencial en la vida de Arguedas. De aquel ambiente nació su profundo amor por la sierra y su gente. Convivió con los indígenas llegando a una profunda identificación con ellos. Aprendió a hablar quechua antes que castellano, que solo llegó a dominar a los 9 o 10 años. (Valcárcel, 1981, pp. 370-371)

Reconocemos que el historiador comete un error en cuanto a la edad que tiene el niño cuando es abandonado, pero la posición de los partidarios de la versión oficial, que hace de José María el segundo hijo de Victoria Altamirano Navarro, huérfano cuando ella fallece a pocos meses de dar a luz al tercer hijo, parece inquebrantable: no deja lugar a dudas e incluso rechaza cualquier debate o controversia. Entre los académicos y críticos literarios más reconocidos, ha sido difícil encontrar a alguien deseoso de lanzarse a averiguar sobre lo que escribió Valcárcel en sus Memorias.

Asimismo, niegan el monolingüismo quechua de los primeros años de infancia que José María había clamado no una sino muchas veces; como en la conferencia en el Centro de Investigaciones Literarias de la Casa de las Américas, en La Habana, en enero de 1968: “El que yo haya aprendido a hablar el quechua no es ninguna excepción, casi todos los niños aprenden a hablar el quechua; por circunstancias muy especiales, yo hablé exclusivamente el quechua más o menos hasta los nueve años" (Arguedas, 2012, XII, p. 531). 
Ante el hecho de que la versión abanquina se corresponde con la de Valcárcel y de que ambas tienen bastantes elementos que encajan con declaraciones del mismo José María o con situaciones de sus relatos y de su vida, extraña que no se encuentren en los medios oficiales ni en las investigaciones preguntas sobre el tema planteado por el historiador en sus Memorias en 1981, especialmente si tomamos en cuenta que Valcárcel falleció en 1987, más de seis años después de publicarlas.

¿Por qué el silencio ante las revelaciones de Valcárcel?

La mayoría de las personas que entrevisté - profesores y estudiantes universitarios limeños- me aconsejaron amablemente que no siguiera enfrentándome con los partidarios de un Arguedas blanco y criado, al igual que ellos, en la lengua materna castellana, aunque lo admitían oriundo del departamento de Apurímac, que todavía en nuestro siglo XXI presenta el porcentaje más elevado de habitantes de lengua materna y cultura quechua ${ }^{1}$.

¡Que me olvidara del tema, me sugerían! Pero eso no cabía en mi perspectiva; en mi manera de entender la literatura es absurdo: me había formado en el concepto de "una vida, una obra", es decir, en la importancia de conocer la biografía, los acontecimientos y las experiencias vitales de un escritor, de todo artista, para entender cabalmente su obra, en la que, conscientemente o no, siempre pone de sí mismo. En el caso de Arguedas, me parecía ineludible conocerlo mejor en su verdad para entender de manera justa sus ficciones; el por qué y cómo conseguía ese tono, esos matices verosímiles, diferentes a los de narradores peruanos de principios del siglo xx como López Albújar o Ventura García Calderón:

Los dos describen al indio como un ser de expresión pétrea, misteriosa, inescrutable, feroz comedor de piojos [...] La novelística de este siglo [xx] comienza con un tema que se refiere a esta zona del país, a la sierra, en donde hay una tremenda y absoluta división entre indios y no indios. Los mistis consideraban a los indios como bestias de las cuales no hay nada que esperar más allá de lo que es una bestia de carga. (Arguedas, 2012, XII, p. 530)

Ni López Albújar ni García Calderón compartieron la vida de los andinos, o lo hicieron muy tangencialmente; ambos eran de la costa, el segundo era limeño. Arguedas aclara lo que, según él, imprime a su visión un carácter especial: la cultura quechua, es decir, la lengua y las tradiciones culturales y religiosas.

Luego de estos narradores, surgen los de nuestra generación, formada principalmente por dos autores: Ciro Alegría y yo. Los dos nacimos en zonas de la sierra, bastante distintas la una de la otra. Ciro nace, como hijo de un pequeño hacendado, en la zona

1 Según los censos de población del 2007 y del 2017, el porcentaje de habitantes que se declaraban de lengua materna quechua fue de $71,5 \%$ y $70,8 \%$, respectivamente. 
de la sierra norte del país, donde ya no hay indios desde el punto de vista cultural, porque los indios de la zona norte casi no hablan el quechua; perdieron muchas de sus tradiciones comunitarias, perdieron sus religiones locales y fueron convertidos a la servidumbre, hay entre ellos menos elementos de cohesión, porque no hay identidad de tipo cultural. (Arguedas, 2012, XII, p. 530)

Es difícil pensar que, sin tener sangre indígena, pudiera proceder a una disección tan minuciosa de la sociedad andina. Por esta razón, me parece que lo más cuerdo es seguir la opinión de Valcárcel y tratar de descubrir el vínculo de Arguedas con la sociedad andina desde lo más esencial, su interior: "Arguedas escribe desde el Perú profundo e integral, a partir de la lengua y la expresión verbal, principalmente desde la 'oralidad narrativa' con una 'elaboración desde adentro (de) la mentalidad indígena'", escribe Javier Mariátegui (1995, p. 91) citando el artículo “El mundo es todas las sangres: Alegría y Arguedas” de Ricardo González Vigil (1991).

Mis continuos viajes al Perú me han permitido conocer el racismo como fuente de silencio y de indiferencia: "Tierra de violencia generada por una sociedad marcada por un profundo desprecio al indio" (Velázquez Cabrera, 2011). Por su parte, el sociólogo y novelista Roberto Reyes T. (2011) aclaró en una conferencia en homenaje a Arguedas que "La cultura andina, estuvo relegada y hasta menospreciada por los habitantes de la capital, sobre todo los que constituían la élite de poder económico e incluso intelectual".

Entonces se explica el silencio de la mayoría de los lectores de Valcárcel, sin duda gente culta, limeños poco deseosos de devolver a los indios andinos la gloria merecida por uno de los suyos y porque, en ese entonces, los libros peruanos se publicaban y vendían en Lima casi exclusivamente. En la sierra no podían ponerse al tanto de lo nuevo para comentarlo. En los años ochenta y noventa, por ejemplo, en el departamento de Apurímac no existía una librería (un comercio dedicado a la venta de libros nuevos de publicación reciente; aunque recibían este nombre los negociosos de papelería, venta de revistas y periódicos, no siempre de primera mano, a veces y por suerte se podían comprar libros de segunda o tercera mano).

En sus ficciones, Arguedas nos hizo ver la sociedad andina de su infancia; sociedad que analizó luego con aguda mirada antropológica. Aquí nos interesa lo que atañe a la palabra "raza":

Entre las "más altas esferas" de la gente poderosa de la sierra y de la costa es posible que se siga considerando al "indio", al "zambo" y al "mestizo", como a individuos inferiores por causa de su nacimiento y su "raza". [...] Basta con repetir que únicamente quienes ignoran los conocimientos elementales de la antropología pueden creer, en el Perú, que cuando se habla de indios alguien se refiere a la "raza". [...] La mezcla racial comenzó con la conquista; ella se hizo en forma tan amplia e indiscriminada que, en un periodo no muy largo, figuraban ya en las clases y aun castas consideradas como 
superiores hombres racialmente mestizos e incluso indios, y a la inversa, en la masa de indios figuraban individuos, mestizos de sangre y aun blancos. [...] Muchos "altos señores" de la región andina son racialmente indios. [...] ¿Quién habla de razas? La palabra indio no designa en el Perú una raza sino un tipo de cultura; lo mismo ocurre con la palabra mestizo o cholo. (Arguedas, 2012, XI, p. 545)

Como cita Cecilia Bustamante (1983, p. 188), Arguedas reivindica su pertenencia a la nación peruana: “Quién soy? Un hombre civilizado que no ha dejado de ser, en la médula, un indígena del Perú; un indígena, no indio".

En conferencias, entrevistas y cartas dejó indicios a veces contradictorios, como él mismo reconoció en carta a John Murra del 17 de marzo de 1968: "Vivo en medio de ciertas contradicciones que no puedo resolver" (Murra y López-Baralt, 1996). En su discurso de recepción del premio Inca Garcilaso de la Vega, en 1968, Arguedas respondió a la búsqueda de identidad cultural: "No soy un aculturado, yo soy un peruano" (Arguedas 1983, V), declaración fundamental que deja entender que no hay indios, quechuas ni blancos, sino solo peruanos cuya cultura es una, con matices, con diversas tradiciones, sin prepotencia de una sobre otra; en suma, una cultura nacional plural que Arguedas presentaba como expresión de los peruanos ${ }^{2}$.

\section{¿EL TRAUMA DE LOS MALOS TRATOS DEL HERMANASTRO?}

Trece años mayor que José María, Pablo Pacheco, el primogénito de la nueva esposa de Víctor Manuel Arguedas, probablemente conocía el origen de ese hermanastro menor que llegó a la casa, de pelo y cutis claros, pero de sangre india, mientras que él tenía la tez oscura y el cabello muy negro y tupido. Era un misti que probablemente envidiaría el cutis, los ojos y el cabello claros del niño. José María lo describía como la maldad hecha hombre; Pablo lo maltrataba físicamente, lo injuriaba como se hacía con los indios y lo obligaba a presenciar sus hazañas sexuales: violaciones de chicas indias que inconscientemente señalan su propia concepción y le dejan heridas psíquicas imborrables, más profundas y dolorosas que la muerte de doña Victoria unos años atrás.

¿Quién tenía entonces un poder de vida y muerte sobre hombres y mujeres viviendo en sus tierras, incluso sobre los no nacidos, sino el amo? El señor Manuel María Guillén, esposo de Amalia, hermana mayor de Víctor Manuel Arguedas - padre de nuestro escritor - era el amo absoluto y autoritario de las haciendas más importantes del distrito. Era un hombre muy piadoso: invitaba a los curas a sus haciendas para que casaran y bautizaran a los siervos que no habían recibido esos sacramentos. ¿Cómo se habrá

2 En Apurímac, en el censo de población del 2017, entre los habitantes de más de 12 años de edad, solo el $1 \%$ contestó que se percibía como de origen blanco, mientras que el 84,1 \% se identificó como de origen quechua. 
enterado don Manuel de la concepción en una de las jóvenes que servían a su esposa? ¿Habrá sorprendido la violación o recibido denuncias? ¿Habrá sido su esposa quien obliga a la sierva a confesar al ver crecer su barriga? Una vez nacido el niño, don Manuel habría podido condenarlo a morir ahogado en el río. En tales casos, esa solía ser la sentencia.

Para fortuna del mundo de la cultura, se salvó José María. Él y su madre pagaron un precio alto con el secreto de la filiación exigido por el omnipotente viejo para proteger el honor de la familia. Bien sabemos lo preguntones que son los niños y cómo suelen repetir las mismas preguntas cuando no reciben una respuesta satisfactoria. Podemos imaginar que, quien dispuso de la vida de todos en sus tierras, también impuso una única respuesta: "Tu madre murió cuando tenías dos años y medio".

Como si se tratara evidentemente de Victoria Altamirano. De tanto repetirlo y oírlo, terminaron todos por creerlo hasta, tal vez, olvidarse del drama original de nuestro escritor, drama que seguía en su inconsciente un trabajo de destrucción interior. Que Victoria Altamirano falleció cuando José María tenía dos años y medio es casi exacto, pero que ella fuera su madre, habría que probarlo. De ser el caso, no hubiera declarado que de su madre no tenía ningún recuerdo. Por lo menos existe esta foto de estudio, tomada en 1912, que pertenece al hermano mayor (Collado Román, 2005, p. 23).

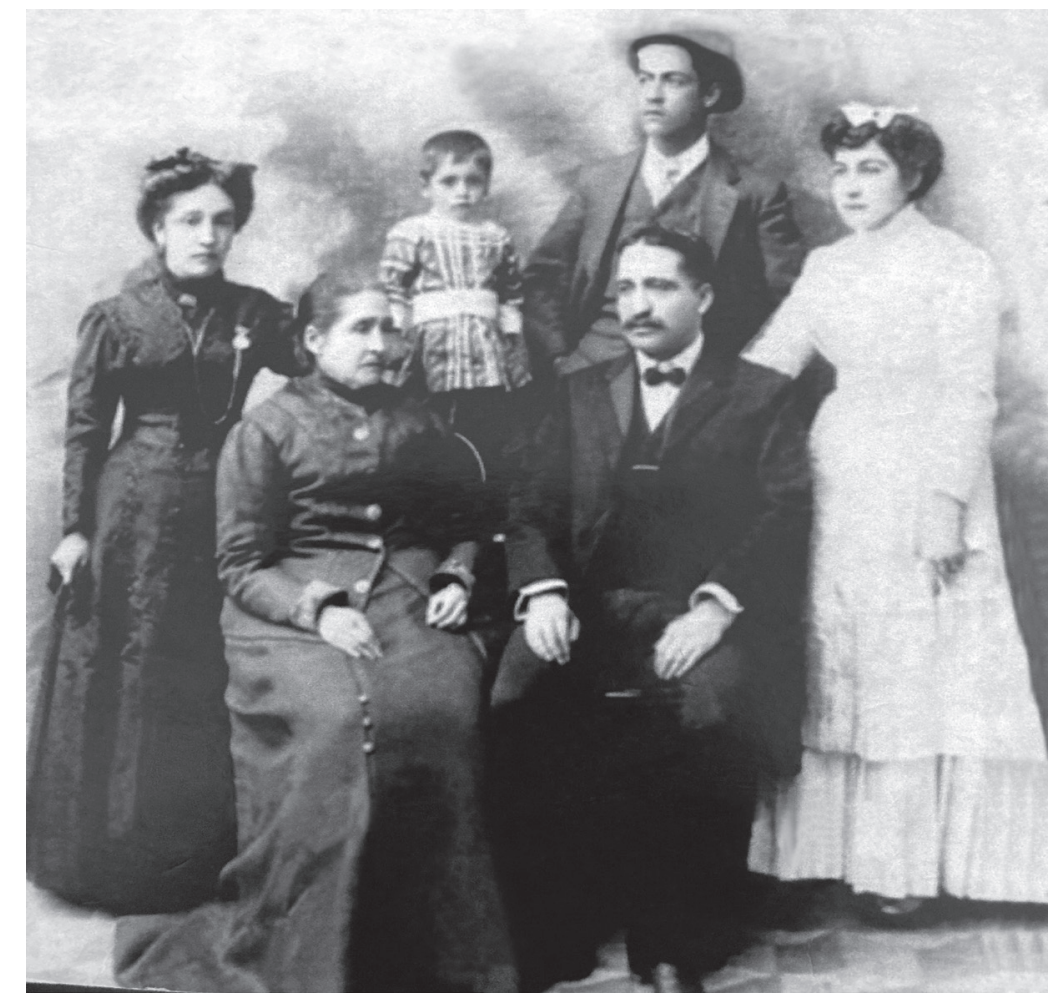


Sentados, figuran el Dr. Víctor Manuel Arguedas, el padre del escritor, y Teresa Arellano (abuela paterna de José María, casada en segundas nupcias con José Manuel Perea de la Rávida). Detrás de ellos, de pie, vestida de negro, están Victoria Altamirano Navarro de Arguedas, el niño Arístides Arguedas Altamirano, hijo mayor de Víctor Manuel y Victoria; José María Perea Arellano, tío de Arístides y José María, y, vestida de blanco, su tía Hortensia Altamirano, viuda de Cornejo. ¿Por qué no posa entre ellos José María que ya tendría entonces por lo menos un año de edad? La figura esbelta de Victoria tampoco tiene huellas de un embarazo reciente; es difícil que fuera la madre biológica del niño José María. Por otro lado, gracias a Rosa Mattos Gutiérrez (entrevistada por Sánchez Lihón, s/f b) tenemos el testimonio de “El abogado Jesús Camacho quien conoció a la persona que crio a Arguedas en Andahuaylas, antes que muriera la señora Victoria Altamirano y quien nos refiere que mientras ella vivió la señora rechazaba al niño José María". ¿Lo rechazaría porque no era hijo suyo? No dudo que, para salvar su honor y el de la familia de su hijo mayor, ella se vio en la obligación de darle su apellido, pero nadie podía obligarla a que le diera su cariño.

\section{BUSCANDO UNA INDIA}

Víctor Manuel Arguedas era un misti de ascendencia española. Los fuertes vínculos que ataban a José María con los indígenas, su profundo arraigo en la cultura indígena, la reivindicación del idioma materno quechua no le venían de su padre; solo podían ser de herencia materna. La familia de Victoria Altamirano era conocida por pertenecer a la "buena sociedad misti" de la ciudad de San Pedro de Andahuaylas. Victoria, la esposa de Víctor Manuel Arguedas, no podía haber sido la madre genitora. Habría que ir a buscar a otra mujer.

$\mathrm{Al}$ apaciguarse el interior del país, después de la tormenta política de los años ochenta, despertó la curiosidad y se soltaron las lenguas en Apurímac, en torno al distrito de Huanipaca. Circulaban voces acerca del escenario del primer relato de Arguedas, "Runa Rupay"3, en el que una hermana de su padre, Amalia Arguedas de Guillén, y su esposo Manuel María Guillén (apodado el Viejo en Los ríos profundos) eran dueños de las cuatro haciendas de aquel distrito de la provincia de Abancay. Rosa Mattos Gutiérrez, oriunda de Huanipaca, ahijada querida de los dueños de las cuatro haciendas del distrito, quienes la bautizaron hace más de noventa años, me contaba que, de niña, veía a José María cuando iba de visita a la casa de su tía, Amalia Arguedas

3 "[...] escrito por encargo de la Dirección del Censo. No es un relato libre. No lo cuento nunca entre mi bibliografía. 'Runa Yupay' quiere decir censo". Carta de Arguedas a Donna Oshbel Levy, 22 de setiembre de 1967 (en Arguedas, 1983, I, p. 163). Era un guía para los profesores en preparación del censo de 1941. Cada colegio recibió tres ejemplares. 
de Guillén: “Llegaba siempre a Huanipaca. Vestía terno, nadie más lo hacía. No hablaba con nadie. Cruzaba la plaza y se sentaba en una piedra de la colina de Cicuca. Me fascinaba verlo. Él pasaba horas mirando un mismo lugar" (Delaune-Gazeau, 2011). La señora recuerda en especial la visita de José María cuando recién había salido del penal El Sexto ${ }^{4}$; dejó testimonio de su encuentro con él en la antología Reflejos de vida, producida por el taller literario del Centro del Adulto Mayor Pablo Bermúdez:

Cuando conocí "Agua" de José María Arguedas y supe que era ese señor flaco, que salía todas las mañanas de la casa de doña Amalia, en mi pueblo de Huanipaca, lamenté no haberle dirigido la palabra, no haberme sentado a su lado y mirarlo a los ojos.

Claro que era pequeña... Me limitaba a seguirlo de lejos cuando subía al cerrito Cicuco. (Mattos Gutiérrez, 2005)

¿Qué podía atraer a Arguedas por esos lugares alejados recién salido del infierno de una prisión limeña? ¿Sería el lugar en donde abrió por primera vez los ojos? ¿El sitio donde empezó a existir? ¿Por instinto sabría que era su origen, "su lugar en el mundo"? Creo que las respuestas están en su obra y en los escritos de quienes han realizado investigación de campo, en especial en Apuntes sobre el nacimiento de José María Arguedas, de Walter Saavedra, director de la revista Tutaykiri, quien, movido por las coincidencias entre lo que le comunicaron amigos y lo que Valcárcel había escrito en sus Memorias, emprendió, además, una pesquisa en la obra literaria, antropológica y etnológica:

Pocos años después, llegó a nuestros oídos la noticia de que José María era hijo de una india de Huanipaca (Abancay). [...] Era un camino que se abría. Había que ir para esa línea. Valcárcel no iba a hacer una afirmación tamaña sin tener pruebas... o sin creer tenerlas. (Saavedra, 2006)

En nota al pie de este texto, el autor narraba:

En un viaje anterior - en realidad de no mucho tiempo antes- que hicimos acompañando a Francisco Xavier Solé Zapatero, tuvimos la oportunidad de escuchar en Abancay, de labios de una jovencita, sin que nosotros hayamos hecho ninguna alusión sobre el particular, esta misma versión que ya por entonces llevábamos. Ella nos decía lo que pensábamos... Mayor razón para volver. (Saavedra, 2006, n. 2)

Y concluía con modestia: "Nuestras indagaciones iniciales no fueron más allá de establecer un nombre para la posible madre: Juanita Tejada” (Saavedra, 2006).

4 En 1961 Arguedas publicó una novela epónima, El Sexto, que muestra la mezcla de tipos humanos encerrados junto con él en ese penal de Lima por los años 1937-1938. Arguedas había sido apresado por haber impedido la visita del embajador italiano de Mussolini a la Universidad de San Marcos. 


\section{ALGUNOS RESULTADOS DE INVESTIGACIÓN DE CAMPO}

Desde los tiempos de José María mucho ha cambiado el Perú, pero se puede esperar que, en aquel paraje alejado, muy apegado a sus tradiciones, permanezca la memoria de la comunidad entre la gente indígena de este siglo. Si parte del secreto fluía entre Abancay y Lima, mucho más se debía de recordar entre los indígenas de Huanipaca. Las descripciones de Rosa Mattos, como las del relato "Runa Yupay", muestran a Huanipaca como un pueblo alegre, solidario. Veamos cómo la reunión por el censo se asemejaba a una familia más bien maternal, en una casa limpia y acogedora, con niños jugando y haciendo bulla:

Los varayok del pueblo barrieron la plaza desde la madrugada, cambiaron cada uno, seis y siete escobas de tantar, y a la salida del sol, en la plaza limpia, correteaban los escolares, y gritando y llamándose de esquina a esquina. [...] los escolares grandecitos ayudaban. (Arguedas, 1983, I, p. 159)

Cuando lo conocí, a inicios de la década del 2000, Huanipaca era un pueblo aislado, de difícil acceso, solitario, donde ya no se veía madreselva, al que se llegaba, después de horas de viaje desde Abancay, por una sinuosa carretera en las laderas del nevado Ampay, ya no tan "nevado" para entonces. La casa donde vivía la familia Tejada Pérez estaba cerca de la plaza. No se había perdido allá el recuerdo de quien fuera la mujer indígena y callada, probablemente verdadera madre del escritor.

En sus Apuntes, Saavedra alterna los resultados de su investigación de campo por las tierras de Huanipaca, con su conocimiento histórico y social del lugar, con sus sentimientos y con entrevistas a ancianos quechuahablantes, familiares de Juanita Tejada. En el 2004 Saavedra fue el primero en pasar por Huanipaca para investigar con su amigo Blandy Gutiérrez, intérprete quechua, quien grabó las traducciones de las entrevistas al castellano: “Los familiares de Juanita Tejada manifiestan de que ella ha trabajado desde los 8 años o 7 en las tierras del patrón...". Saavedra explica:

Obtuvimos algunos testimonios que nos permitieron afirmar, con algo más de certeza, la hipótesis de que Juanita Tejada efectivamente había tenido un hijo nacido en la ex hacienda Karkeki (ubicada en Huanipaca, Abancay). Por las referencias similares que encontramos en las obras de Arguedas, aceptamos que el niño nacido fue precisamente él. [...] Era la Semana Santa de 1910. Como acostumbraba para sus fiestas, Guillén la celebró con la presencia de franciscanos cusqueños. Llegó de visita a Karkeki Víctor Manuel Arguedas Arellano. Es por esta fecha que seduce a Juanita, que ronda los 14 años de edad. (Saavedra, 2006)

Curiosamente, en la obra narrativa de Arguedas se encuentran varias escenas de ese tipo. En Mar de harina, la niña seducida, de 13 años de edad, se llama Juanita: un padre llega al billar muy molesto y le grita al propietario: “'Desvirgada, endelante de mí, la Juanita! (Arguedas, 1983, I, pp. 269-270). Relata Saavedra que el año siguiente: 
Cuando los franciscanos se van de Karkeki, después de la Bajada de Reyes de 1911, el niño les es entregado para que lo hicieran llegar al padre, Víctor Manuel Arguedas, en Andahuaylas [y cita a una hija de Pablo Tejada Guillén]: “Manuel María Guillén no habrá querido... ¿Qué cosa habrá sentido? Vergüenza (...) ¿Por qué le habrá dado su hijo [de Juanita] a los curas?". (Saavedra, 2006)

Siempre ese sentimiento vergonzoso de los mistis que temían el lastre de ser familiares o descendientes de indígenas, lo que, por cierto, está en el origen de conflictos raciales.

Si la Bajada de Reyes se celebra el 6 de enero, José María no puede haber nacido el 18 de enero de 1911, como figura en su partida de bautismo. No sería el único error del documento:

El profesor Gutiérrez [intérprete de Saavedra] manifestó que, en la partida de bautismo de Arguedas, en el lugar donde se escribía el apellido materno había una " $\mathrm{T}$ " como letra inicial. Esta " $\mathrm{T}$ " se convertía en " $\mathrm{A}$ ", para dar cabida a la letra con que se inicia el apellido "Altamirano", apellido con el que fue bautizado en Andahuaylas José María (esto le fue narrado al profesor Gutiérrez por Carmen María Pinilla). (Saavedra, 2006)

Rosa Mattos confirma el hecho en varias ocasiones. Al igual que la Dra. Pinilla, pudo ver la partida (Delaune, 2011; Sánchez Lihón, s/f b). Según los recuerdos de los ancianos en Huanipaca, es muy posible - unos dicen probable - que, al morir Victoria de Arguedas, José María regresase a Karkeki con Juanita, y que otra vez le fuera arrebatado al volver a casarse Víctor Manuel. "Muerta la señora Victoria Altamirano, la criada Juanita Tejada Gutiérrez recuperó a su hijo, regresando a su cuidado. Luego el niño volvió a ser recuperado por la familia Arguedas" (Saavedra, 2006). Ninguna consideración psicológica ni afectiva de parte del patriarca. Sabemos que en sus últimos años, Juanita perdió la razón y se la pasaba hablando del niño, andaba llorando y llamando "Mi niño", tal vez lamentando guardar el secreto de su maternidad.

Lo cierto es que Saavedra volvió de su viaje convencido de la pertenencia de José María Arguedas a dos estirpes culturales del Perú, la criolla por el padre, la indígena andina por la madre, resaltando además lo que se desprendía de los textos de nuestro escritor: su nacimiento de una mujer india. Consiguió reconstruir la infancia de Arguedas y dar un nombre, una existencia, a la madre biológica.

De lo que encontramos en Huanipaca, lo que más nos conmovió e impresionó, fue que los sobrinos nietos de Juanita, tenían rasgos parecidos a los de José María, especialmente Alejandro - que vive en la ex casa hacienda de Karkeki-. Alejandro Tejada Guillén (de 75 años) era la viva imagen de José María Arguedas (muerto a los 58 años). Esta evidencia gráfica encontrada nos decía habíamos llegado al origen de todo este asunto. (Saavedra, 2006, subrayados de la autora) 
El autor aclara en nota al pie que, sorprendidos por la similitud de rasgos de los hombres de la familia Tejada con José María Arguedas, no querían dejarse engañar por su imaginación:

Hicimos que Alejandro Tejada tuviera en sus manos los "Textos esenciales" de Arguedas editados el 2004 por Carmen María Pinilla Cisneros, que tiene en la portada un nítido retrato de José María Arguedas, y nos maravillamos de la semejanza existente entre uno y otro rostro. El mismo Alejandro Tejada lloraba cuando veía la foto y escuchaba lo que le contábamos nosotros. Él nos dijo no tenía noticia de un posible pariente con la fama de éste que le mostrábamos, como tampoco la tenían sus hermanos Lázaro y Néstor. Pero sí conocían de esto sus hermanos mayores Pablo y Melchor. Los sobrinos de Juanita Tejada tienen un recuerdo grato de ella. Especialmente Alejandro, que manifiesta que fue su preferido... y el parecido explicaba el porqué. (Saavedra, 2006, n. 3)

Los interesantes datos que da Saavedra demuestran sus conocimientos de las tradiciones locales y la seriedad de sus investigaciones:

Recordemos aquí que en Huanipaca, a la criatura recién nacida, la aislaban rigurosamente, junto a su madre, durante un mes, para evitar que muriese pues estaba indefenso contra todas las fuerzas malignas. Es difícil, dada la religiosidad de Manuel María Guillén, que el niño no fuese bautizado estando los franciscanos allí. Igualmente es difícil que el viaje se produjese antes de cumplirse el mes de aislamiento. ¿Esperaron los franciscanos como un favor especial? ¿O, si se fueron antes, Juanita tuvo que irse también para proteger al niño? (Saavedra, 2006)

Saavedra cita a Luz Marina Tejada: “Juanita tuvo un hijo. No lo amamantó. Lo siguió hasta que él tuvo 5 o 6 años"; y lo que resume en castellano el profesor Gutiérrez, de lo que dijeron los ancianos de la familia Tejada en quechua:

"Juanita ha trabajado allí y muy posiblemente haya tenido un hijo que andaba con ella en la hacienda y después desapareció. Esto daría a entender más o menos que cuando el chico lo llevan a Andahuaylas, de allí regresa acá (a Abancay) y hace sus estudios". [...] Es posible que José María regresase a Karkeki al morir Victoria Altamirano. (Saavedra, 2006)

Saavedra no buscaba sino la verdad del nacimiento de José María. Al empezar su investigación, no tenía una opinión previa. Conocía bien la obra escrita de Arguedas y también las tradiciones y costumbres andinas.

Como ya hemos expuesto, Valcárcel fue para José María Arguedas más que un colega, un amigo, un modelo, un confidente. No tenía ninguna razón para inventar lo que escribió, ninguna razón para engañar a nadie. Sin embargo, Merino, a pesar de su voluntad de conocer de manera más certera la personalidad de Arguedas — “Tratar de comprender la vida de José María Arguedas demanda ir más allá de su curriculum vitae; no quisiéramos errar en tomar párrafos de sus novelas como datos biográficos", escribió (1991, p. 114) -, no toma en cuenta a Valcárcel y se niega a considerar los párrafos de las 
novelas en los que José María se las ingeniaba para revelarse. Su proposición es cierta; el currículo podría ser el de un misti: una niñez pobre, un huérfano, desgraciado, mal amado, maltratado por la familia de la madrastra, a pesar de o por su apariencia física de criollo, blanco.

Esta postura impide comprender el destino de un hombre que se suicidó justo cuando alcanzaba una meta personal: un puesto que le permitiría influir en la educación de los jóvenes estudiantes y que le brindaría reconocimiento social. Merino prefiere quedarse entre los seguidores de la versión oficial, la de los criollos que hasta estos días desprecian a los indígenas andinos. Ni ella ni sus pares han hecho caso de lo que escribió Javier Mariátegui, que en una época fue médico de José María. En un artículo publicado por la revista Psicopatología en 1995 constata que era difícil encontrar la medicación adecuada porque José María reaccionaba con una sensibilidad extrema, lo que se había observado también entre la población indígena: “José María era extremadamente sensible a los fármacos y acusaba mayormente los efectos colaterales (observación por otro lado frecuente entre los pacientes indígenas o mestizos a predominio indio)". En ese artículo, Mariátegui plantea la pregunta que toda la vida atormentó a José María, a la que, sin embargo, pocos intelectuales han intentado dar respuesta. La mayoría se ha quedado en la denegación, como hemos visto.

Velázquez Cabrera no se deja convencer por los relatos de Saavedra; los califica de "atrevidas especulaciones", aunque en su artículo se acerca a la clave del secreto:

Es muy poco probable que José María haya estado entre los 3 y los 6 años viviendo con su madre Juanita y que ningún recuerdo le haya quedado de esa convivencia. La idea de que Arguedas negara su origen iría a contrapelo de todos sus pronunciamientos acerca de su proximidad a la cultura quechua. [...] En el caso de ser cierta la maternidad de Juanita Tejada, este velo indica que o bien José María no volvió nunca a verla o si la volvió a ver lo hizo sin saber que era su madre. (Velázquez Cabrera, 2011, subrayados de la autora)

Hugo Chacón, autor, entre otras obras, de Arguedas, biografía y suicidio (2018) me comentó el caso de conocidos suyos que se enteraron de que los peones indígenas de la pequeña hacienda familiar eran en realidad sus deudos. Dándose cuenta de que recibían el pésame, preguntaron a su madre, quien a duras penas contestó que eran familiares, y además confesó que ella tenía sangre judía. Secreto de familia bien guardado. El paso del tiempo había hecho cada vez más difícil la revelación por temor a perjudicar el porvenir de los hijos. Los padres consideraban un lastre ese mestizaje.

Chacón reaccionó vivamente ante la posibilidad de la doble sangre y la doble cultura de José María. Por las razones expuestas en el párrafo anterior, decidió investigar a partir de las numerosas declaraciones de Arguedas de tener el quechua como lengua 
materna. Llegó a la convicción de que José María no había podido nacer de Victoria Altamirano Navarro de Arguedas. Así, Chacón se une y apoya, como evidente, la tesis de Saavedra, de Rosa Mattos, de Danilo Sánchez Lihón y nuestra, iniciada por Valcárcel: la madre biológica de José María era una indígena quechuahablante llamada Juana o Juanita Tejada; seducida, violada por Víctor Manuel Arguedas durante una visita a su hermana mayor, Amalia Arguedas de Guillén, en sus haciendas de Huanipaca, en Abancay. Para Chacón, el día que el Perú reconozca que Arguedas nació de padre criollo y de madre indígena, habrá dado un gran paso hacia adelante en el camino que permitirá hablar de una nación peruana.

\section{DESDE EL ÚTERO}

Antes de concluir, quiero hacer una digresión desde las posiciones psicológicas que han estudiado la importancia de la vida intrauterina y del entorno de los primeros días de vida en el desarrollo del ser humano: para Melanie Klein (1882-1960), una de las fundadoras del psicoanálisis - y con base en los descubrimientos de Freud- el inconsciente nace en la barriga de la madre, de ahí el papel primordial de las relaciones del bebé con las personas que atienden su nacimiento y sus primeros días (v. Klein, 1959 y 1968; Arnoux, 2011; Lauret y Raunaud, 2008).

Posteriormente, la hipnoterapeuta Sophie Guedj Metthey, autora de un libro titulado Vivir y transmitir lo mejor durante el embarazo, y siguiendo al sofróloga Claude Imbert, escribe:

L'importance de la vie intra utérine et de la naissance a été une des découvertes qui máa le plus marquée dans mon expérience de thérapeute. [...] Une grande partie des peurs et du sentiment de non reconnaissance dont souffraient beaucoup de mes patients semblaient associées à ce passage de la vie intra utérine et de la naissance. [...] Il semble que le fœetus enregistre le vécu et les émotions de ses parents comme une bande magnétique et qu'il ressente ce qui l'entoure de manière intense et émotionnelle, sans avoir la possibilité de le mettre en perspective.

$\mathrm{Au}$ travers de l'expérience de mes patients, je remarquais que ce n'était pas tant les évènements en eux-mêmes mais davantage la façon dont leurs parents les avaient vécus et ressentis. [...] Ce qui semble marquer le plus durablement l'enfant est le rejet de sa mère ${ }^{5}$. (Metthey, 2012)

5 “La importancia de la vida intrauterina y del parto ha sido uno de los descubrimientos que más me impactaron en mi experiencia de terapeuta. [...] Gran parte de los terrores y del sentimiento de la falta de reconocimiento que padecían muchos de mis pacientes parecía estar asociada con aquel paso por la vida intrauterina y por el nacimiento. [...] Parece que el feto graba lo vivido y las emociones de sus padres como una cinta magnética y que experimenta el entorno intensa y emotivamente, sin poder ponerlo en perspectiva.

A través de la experiencia de mis pacientes comprobaba que [...] lo que más duraderamente impacta al niño es el rechazo de su madre". 
Metthey reflexiona sobre el impacto de la vida intrauterina en nuestra vida: “¿Y si todo se decidiera en ese momento? [...] Nuestra historia no es una fatalidad, sino una oportunidad de crecimiento personal y espiritual" (Metthey, 2012).

Estos descubrimientos me han ayudado a entender cómo, aunque nadie se lo hubiera dicho (a menos que por crueldad el hermanastro lo hubiera tachado de "indio"), José María Arguedas presentía que pertenecía al mundo indígena y su desgracia fue que los pocos que lo sabían con certeza no se lo confirmaron.

No puedo estar totalmente de acuerdo con Chacón cuando menciona "La serie de evidencias que Arguedas fue dejando como peldaños de acceso a una biografía cierta que parecía interesado en difundir y, al mismo tiempo, él mismo revestía de un velo de secretismo y, quizá, vergüenza" (Chacón, 2018, p. 10). Yo diría más bien que esa "serie de datos que Arguedas fue dejando", revestía para él mismo un velo de dudas que no pudo resolver.

Quien lee atentamente su obra no puede aceptar que Arguedas pudiera avergonzarse de su madre indígena; al contrario: siempre defiende, aclara la cultura y las costumbres indias andinas desde el interior.

Por amor a su hijo, a su "niño", Juanita Tejada no le revelaría su identidad, sabiendo del drama que hubiera estallado de no guardar para ella el secreto. Juanita debe ser considerada una madre ejemplar que vio el interés de su hijo antes que su propia felicidad. No se enteraría del malestar que provocó en José María la incertidumbre acerca de quién lo dio a luz; tampoco conocería esta declaración suya: "Yo no entendí nunca bien el mundo de mi padre" (Arguedas, 1975, p. 47). Dicho sea de paso, no se encuentran en la obra de Arguedas frases como esta en referencia al mundo indio.

Mejor que el Inca Garcilaso de la Vega, que escribía desde fuera, desde España, para dar a conocer la historia y las tradiciones incaicas, Arguedas es el primer autor que reveló al mundo las costumbres y vivencias de los habitantes de los Andes peruanos, siendo él mismo, sin que lo supiera con certeza, uno de ellos.

El amor que le diera a su desconocida madre indígena abanquina, igual lo recibió, sin saber, de ella:

Le souvenir du bonheur matriciel avec la jouissance d'absolu qui l'accompagne est si présent dans le préconscient qu'il est le but final recherché par tous les humains. Ce pourquoi ces derniers projettent le retour à l'état inanimé comme but ultime et essentiel de leur vie, bref comme le seul et unique bonheur dans la plénitude, où le Tout est en accord avec le Monde. Au cas où ce serait pas envisageable les hommes ont imaginés divers subterfuges culturels et cultuels pour y parvenir tels divers purgatoires et autres réincarnations. Par ailleurs, il est aisé de comprendre que la 
mort est la plupart du temps assimilée pour les mêmes raisons au retour vers ce bonheur matriciel ${ }^{6}$. (Psychanalyse.com, 2010)

De todo lo anterior podemos afirmar que el estado civil oficial de José María Arguedas no correspondía a la realidad de su nacimiento que pocas personas conocieron: la incertidumbre en cuanto a su filiación materna lo perturbó toda la vida. A eso y al amor que le brindó su madre Juanita, quien lo cuidó durante su primera infancia sin que él supiese quién era, debemos el tesoro literario que permite que nos acerquemos a la cultura indígena surandina peruana.

\section{REFERENCIAS}

Arguedas, J. M. (1975). Testimonio (sobre preguntas de Sara Castro Klarén). Hispamérica IV(10), pp. $45-54$.

Arguedas, J. M. (1983). Obras completas. Tomos I-V. Horizonte.

Arguedas, J. M. (2012). Obras completas. Segunda Serie, tomos VI al XII (correspondientes a la Obra antropológica y cultural, vols. 1 a 7, 1992). Horizonte.

Arnoux, D. J. (2011). Melanie Klein. (Col. Psychanalystes d'aujourd'hui). PUF.

Bustamante, C. (1983). Una evocación de José María Arguedas. Instituto Internacional de Literatura Iberoamericana.

Chacón, H. (2018). Arguedas, biografía y suicidio. IIPCIAL, Fondo Editorial.

Collado Román, H. (2005). José María Arguedas Altamirano. Biografía. Editorial San Marcos.

Delaune-Gazeau, G. (Junio de 1991). Representación de la ciudad en la literatura "indigenista" peruana. [Memoria de maestría, director: Pr. Erich Fisbach]. Universidad de Angers.

Delaune-Gazeau, G. (2011). Conversación con Rosa Mattos Gutiérrez en su casa de Jesús María. Archivos de la autora.

González Vigil, R. (1991). El mundo es todas las sangres: Alegría y Arguedas. En El Perú es todas las sangres. Pontificia Universidad Católica del Perú, Fondo Editorial.

Klein, M. (1968). Essais de psychanalyse. Trad. del original Contributions to Psycho-analysis (Hogarth Press) por Marguerite Derrida. Payot.

Klein, M. (1959) La psychanalyse des enfants. (J. B. Boulanger, Trad.). PUF.

Lauret, M., y Raunaud, J.-P. (2008). Melanie Klein une pensée vivante. PUF.

6 “El recuerdo de la felicidad matricial con el goce del absoluto que la acompaña está tan presente en el preconsciente que es el objetivo final perseguido por todos los seres humanos. Es por esta razón que estos últimos proyectan el retorno al estado inanimado como el fin último y esencial de su vida, en definitiva como la única felicidad en plenitud, donde el Todo está en armonía con el Mundo. En caso de que esto no sea posible, los hombres han imaginado diversos subterfugios culturales y rituales para lograrlo, como varios purgatorios y otras reencarnaciones. Además, es fácil comprender que la muerte en la mayoría de los casos es asimilada por las mismas razones al regreso hacia esta felicidad intrauterina" (traducción de la autora). 
Mariátegui, J. (1995). Arguedas o la agonía del mundo andino. Psicopatología, 15(3) 91-102. [Hay reproducción reciente en Acta Herediana 48 (2015). https://doi.org/10.20453/ ah.v48i0.2224].

Mattos Gutiérrez, R. (Abril del 2005). ¿Florencia? En Ríos, C. (Coord.) Reflejos de vida. Taller literario del Centro del Adulto Mayor Pablo Bermúdez. EsSalud / Saar Editores.

Merino de Zela, M. (1991). Vida y obra de José María Arguedas. En R. Montoya (Comp.). José María Arguedas, veinte años después: huellas y horizonte, 1969-1989. Universidad Nacional Mayor de San Marcos, Fondo Editorial.

Metthey, S. (2012). Vivre et transmettre le meilleur pendant sa grossesse : de l'importance de la vie intra utérine dans l'épanouissement de l'enfant. Souffle d'Or.

Murra, J., y López-Baralt, M. (1996). Las cartas de Arguedas. Pontificia Universidad Católica del Perú, Fondo Editorial.

Pinilla, C. M. (2002). Cartas del Archivo José María Arguedas de la Pontificia Universidad Católica del Perú. Pontificia Universidad Católica del Perú, Fondo Editorial.

Psychanalyse.com (20 de octubre del 2010). Respuesta del Webmaster en la entrada "vie intra-utérine" en el foro del portal de internet. http://psychanalyse.com/forums/ forum-sur-la-psychanalyse/359-vie-intra-uterine/.

Reyes T., R. (Enero del 2011). Homenaje a la obra de José María Arguedas. Ponencia en homenaje a Arguedas realizado en la Universidad Nacional Mayor de San Marcos, manuscrito proporcionado por el autor.

Sánchez Lihón, D. (s/f a). 18 de enero de 1911, nace: Arguedas, Apu tutelar nuestro. En Espacio Latino (portal en internet, sección Instituto del Libroy la Lectura del Perú, textos del autor). http://letras-uruguay.espaciolatino.com/aaa/sanchez_lihon_danilo/18_de_enero_ de_1911.htm

Sánchez Lihón, D. (s/f b). Arguedas, el hijo ajeno. En Espacio Latino (portal en internet, sección Instituto del Libro y la Lectura del Perú, textos del autor). http://letras-uruguay.espaciolatino.com/aaa/sanchez_lihon_danilo/arguedas_el_hijo_ajeno.htm

Saavedra, W. (22 de julio del 2006). Apuntes sobre el nacimiento de José María Arguedas. El Diario Internacional. http://www.eldiariointernacional.com/spip.php?article346

Valcárcel, L. E. (1981). Memorias. Instituto de Estudios Peruanos.

Velázquez Cabrera, V. H. (2011). Centenario de José María Arguedas. En Narratura (blog del autor). http://narratura.blogspot.com/2011/10/centenario-de-jose-maria-arguedas.html

\section{OTRA BIBLIOGRAFÍA CONSULTADA}

Brando, O. (9 de enero del 2004). José María Arguedas. Escribir contra la muerte. El País Cultural. Reproducido en Espacio Latino (portal en internet, sección del autor). http:// letras-uruguay.espaciolatino.com/brando_oscar/escribir_contra_la_muerte_jose_ maria_arguedas.htm 
Castro Klarén, S. (1973). El mundo mágico de José María Arguedas. Instituto de Estudios Peruanos. Chacón Málaga, H. (2017). Nación andina. IIPCIAL, Fondo Editorial.

Dolto, F. (1987). Tout est langage. Vertige du nord/Carrere.

Echegaray Vivanco, L. (2018). Abancay Siglo xx, trazos de su historia. Edición del autor.

Eliacheff, C. (2018). Françoise Dolto Une journée particulière. Flammarion.

Forgues, R. (1995). Arguedas: Documentos inéditos. Empresa Editora Amauta S.A.

García Miranda, J. J. (2002). La tradición y el cambio de la cultura andina en Arguedas. Arguedas vive. Instituto Nacional de Cultura.

Guedj Metthey, S. (2013). Vivre et transmettre le meilleur pendant sa grossesse. Souffle d'Or.

Huamán, C. (2004). Pachachaka, Puente sobre el mundo, narrativa, nemoria y símbolo en la obra de José Maria Arguedas. Universidad Nacional Autónoma de México.

Imbert, C. (2008). Initiation prenatale: l'alchimie d'une nouvelle résilience. Visualisation holistique.

Lemogodeuc, J.-M. (1991). Significados y riesgos del realismo autobiográfico en la obra de José María Arguedas. En H. Pérez y C. Garayar, José María Arguedas. Vida y obra. Amaru Editores.

Lévano, C. (2011). Arguedas, un sentimiento trágico de la vida. Universidad Inca Garcilaso de la Vega, Fondo Editorial.

Nomberto Bazán, V. (2002). La interculturalidad en José Maria Arguedas. Arguedas vive. Instituto Nacional de Cultura.

Soto Sulca, R. (2002). Lo andino y lo moderno en José María Arguedas. Arguedas vive. Instituto Nacional de Cultura.

Urello, A. (1974). José María Arguedas: el nuevo rostro del indio. Librería Editorial Juan Mejía Baca.

Vargas Llosa, M. (1996). La utopía arcaica: José Maria Arguedas y las ficciones del indigenismo. Fondo de Cultura Económica. 